\title{
Assessing the relationship between inundation and diarrhoeal cases by flood simulations in low-income communities of Dhaka City, Bangladesh
}

\author{
Masakazu Hashimoto ${ }^{1}$, Tadashi Suetsugi ${ }^{2}$, Yutaka Ichikawa ${ }^{2}$, Kengo Sunada ${ }^{2}$, \\ Kei Nishida ${ }^{2}$, Naoki Kondo ${ }^{3 *}$ and Hiroshi Ishidaira ${ }^{2}$ \\ ${ }^{1}$ Disaster Prevention Research Institute, Kyoto University, Japan \\ ${ }^{2}$ International Research Centre for River Basin Environment, University of Yamanashi, Japan \\ ${ }^{3}$ Interdisciplinary Graduate School of Medicine and Engineering, University of Yamanashi, Japan
}

\begin{abstract}
:
We quantitatively investigated the relationship between flood conditions and the incidence of diarrhoea caused by flooding in Dhaka City, Bangladesh, by using a twodimensional flood simulation model. We performed flooding simulation in target areas, and the simulated results were compared to diarrhoeal morbidity. Diarrhoea causes were assessed through home-visit morbidity surveys; these surveys were conducted three times in different phases of the rainy season (pre, mid and post-monsoon) in 10 low-income communities in flood-prone areas of Dhaka City, targeting children below five years of age. The results revealed that flooding influences the morbidity of diarrhoea, as increased morbidity was identified in almost all communities in the mid-monsoon season. However, cases with a predisposition of diarrhoea such as socioeconomic status were also identified, as morbidity was observed in pre- and post-monsoon seasons when flooding did not occur. Furthermore, morbidity was higher in areas with maximum flooding depth of 0.7$1.2 \mathrm{~m}$ than that in areas with maximum flooding depth of $0.1-0.2 \mathrm{~m}$ in each season. Consequently, we found that the gradient of diarrhoeal vulnerability is affected by predisposing factors such as socioeconomic status, and its influence is maintained throughout the rainy season.
\end{abstract}

KEYWORDS flooding analysis; Dhaka City; waterborne disease; diarrhoeal incidence; morbidity

\section{INTRODUCTION}

Every year, around 2.5 billion children under five years of age suffer from diarrhoea, and more than half of these cases occur in Africa and South Asia, where bouts of diarrhoea are more likely to result in death or other severe symptoms (UNICEF and WHO, 2009).

Among South Asian countries, Bangladesh is a representative country with high risk of diarrhoea, as well as years of particularly severe flooding. About 51,000 children die from diarrhoea every year in Bangladesh, and the country ranks seventh in the world in this regard (UNICEF et al., 2009). In Dhaka City, the capital, numerous children die each year from diarrhoea. They are easily affected by it, especially during severe flooding. In August 2007, when a severe flood occurred, the number of diarrhoea cases was three times higher than that in August 2006, when severe floods did not occur (ICDDR B, 2007).

The situation is severe in low-lying and low-income communities in urban areas especially. Since people tend to live in simple built houses such as corrugated iron houses, they are sensitive to the natural environment, such as temperature, humidity, rainfall and flooding (Hashizume et al., 2008, 2009). In particular, children are highly exposed to diarrhoeal incidence in this environment, as they lack the acquired immunity and may have played in contaminated floodwaters. Therefore, we need to quickly find a solution for decreasing the risk of diarrhoeal incidence in low-income communities and understand the relationship between the natural environment and diarrhoeal incidence.

Among several natural factors, flooding tends to largely affect the deterioration of the hygienic environment, and such cases were reported in several countries (Baqir et al., 2012). Therefore, health risks, including the incidence of diarrhoea from flooding, are associated with the extent and depth of flooding (Reacher et al., 2004). For this reason, flood simulations and their ability to estimate diarrhoeal incidence are necessary to mitigate the damage and loss from flooding in urban areas. Recently, Kazama et al. (2012) used numerical flood simulation models to estimate diarrhoeal incidence around Phnom Penh City, Cambodia. The study demonstrated that a quantitative risk assessment using a flood simulation model was useful for reducing the risk of infection.

Several researchers have studied the relationship between flooding and waterborne disease (Kunii et al., 2002; Ahern et al., 2005; Schwartz et al., 2006; Harris et al., 2008). However, only a few studies have focused on low-income-community areas. Mollah et al. (2009) targeted only people living in low-income communities, and their results indicated that diarrhoeal incidence is more severe in flood-prone areas than in other areas. However, the study was unable to evaluate the risk based on quantitative flood data. Therefore, the relationship between flooding and diarrhoeal incidence needs to be clarified based on quantitative data.

A numerical flood simulation model is a useful tool for quantitatively evaluating flooding, which enables researchers to qualitatively evaluate hazard and health risk caused by flooding; however, it has disadvantages because of insufficient datasets in developing countries. Mark et al. (2004) conducted flood analysis in Dhaka City by accurately con-

Correspondence to: Masakazu Hashimoto, Disaster Prevention Research Institute, Kyoto University, Shimomisu, Yoko-oji, Fushimi-ku, Kyoto 6128235, Japan. E-mail: hashimoto.masakazu.5e@kyoto-u.ac.jp *Present address: Department of Health and Social Behavior / Health education and Health Sociology, School of Public Health, The University of Tokyo, Japan 
sidering the drainage and sewerage system; however, the target area was limited to only a part of Dhaka City. On the other hand, our research team conducted a flood analysis study that targeted the entire city. However, the flood simulation model did not properly consider the drainage system and the simulation only focused on one month out of a sixmonth rainy season (Hashimoto et al., 2012).

Therefore, this study aims to 1) simulate a flood throughout the monsoon period for the entire city using a numerical model by considering drainage and sewerage and 2) quantitatively clarify the relationship between flood-prone areas and diarrhoeal incidence in the three different seasons (pre, mid and post-monsoon) within Dhaka City.

\section{STUDY AREA}

The targeted area is an urban area of Dhaka City, the capital of Bangladesh (Figure 1). The total area of the city is $360 \mathrm{~km}^{2}$ and its population in 2011 was about 16 million. It is the eighth largest city in the world (WorldBank, 2010). The area consists of flat land, and it is mainly located on an alluvial terrace surrounded by rivers. The Balu River passes through the eastern side of the city, and the Turag and Briganga Rivers are on the western side. The surface elevation of the area ranges between $1 \mathrm{~m}$ and $14 \mathrm{~m}$ above mean sea level (JICA, 1991). The climate in Dhaka City is influenced by subtropical monsoons, with two monsoonal wet seasons from May to October and a dry season from

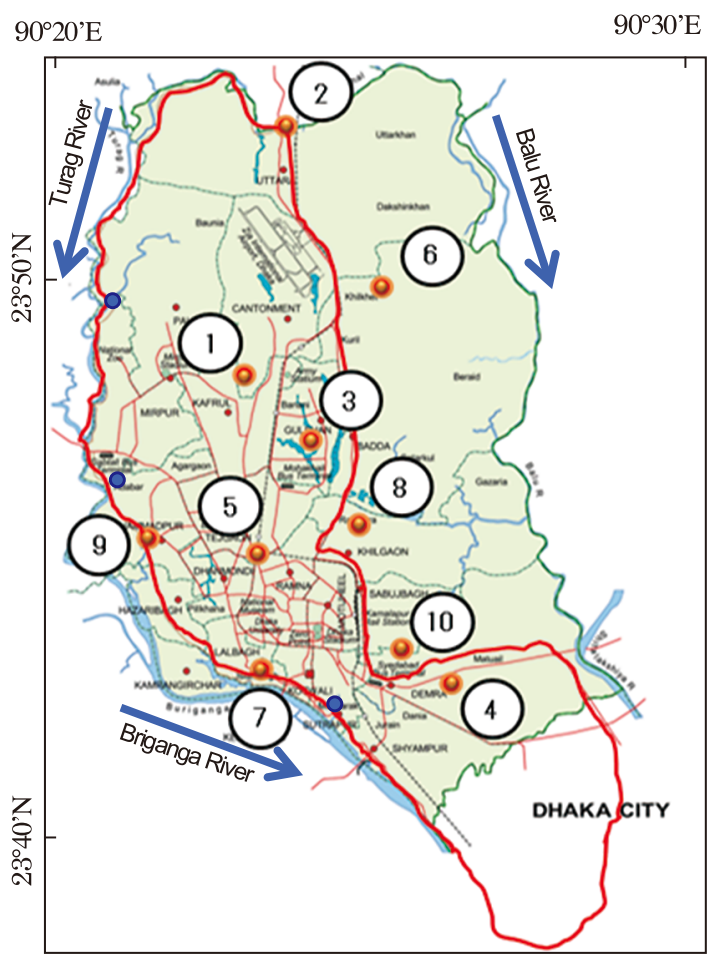

Figure 1. Study area (Dhaka City). The red line indicates the surrounding embankment. The orange dots indicate the locations of low-income-community areas. The numbers in black circles indicate the number of low-income communities. The blue dots indicate the locations of pump stations
November to April. The mean annual precipitation is approximately 2,000 mm.

Since urbanization has rapidly occurred in this area, the time for reaching peak runoff has become shorter. Built-up areas have increased from $11.1 \%$ of the total city area in 1960 to about 49.4\% in 2005 (Dewan et al., 2009). Thus, rapid population growth and the accompanying urbanization have led to deterioration of the hygienic environment and an increase in the risk of floods. Furthermore, narrow floodplains and bottlenecks that occur in the river stream due to housing complexity can lead to overflowing during rainy periods. Floods are also worsened by the inadequate sewerage system. The prevalence of water supply in Dhaka is $18 \%$ (Azharul Haq, 2006), and sewage is 30\% (ADB, 2007); however, the spread has been delayed in low-income communities because fee collection is difficult. Consequently, contaminated floodwaters can easily affect residents.

\section{METHODOLOGY}

\section{Epidemiological data}

Data related to epidemiology were obtained through home visit surveys by Mollah et al. (2009). They conducted a biweekly survey in April (pre-monsoon), September (mid-monsoon) 2007 and January (post-monsoon) 2008 via questionnaires and interviews of mothers of children under five years of age. The number of children who got diarrhoea was surveyed, and morbidity was calculated in each lowincome community. In Dhaka City, there are more than 3,000 low-income communities (MoEF et al., 2006). Ten low-income communities were chosen as target areas, selected by considering flood type over the past 5-10 years. Thus, we numbered the areas as short duration (No. 1, 2, 3), long duration (No. 4, 5, 6), persistent flooding (No. 7, 8, 9 ) and no flooding (No. 10). Flooding data were also obtained by Mollah et al. (2009) from interviews with authorities and the residents concerned, as well as through onsite measurements. In this study, each 'low-income community' was located within $1 \mathrm{~km}$ of the Urban Development Centre Project offices of the Slum Development Department of Dhaka City Corporation, and the number of children in the study totaled 707 from 350 households.

\section{Diarrhoea incidence exposure}

In the interview survey that our research team conducted in September 2010, information about the route of infectious diarrhoea was collected for each low-income community. We visited the low-income-community areas one by one and obtained the answer to the question; 'Why did your children get diarrhoea during flooding conditions?' Five to ten adults were randomly chosen per area. According to the survey results, it was found that children are mainly infected when they play in floodwater. This also supports the result of Rashid (2000). As mentioned in his paper, playing in a flooded place is one of the troubling hazards. Therefore, if the water depth is high, children can easily touch their mouths after their hands touch the floodwater.

Furthermore, Mollah et al. (2009) also discussed the relationship between socioeconomic status and more severe flooding conditions. People in lower socioeconomic positions tend to live in worse flooding conditions, and this is a 
strong environmental hazard for diarrhoea. These people also tend to be ignorant in terms of sanitation, which also seriously increases the risk for diarrhoeal incidence.

Hence, in relation to the risk of children being infected, we assumed that a high flood depth increased access to contaminated water, and long flood duration increased opportunities for contact with the contaminated water. Therefore, in this study, we used maximum flood depth, maximum flood duration and accumulated flood depth as indices to express the likelihood of an area being flooded. Then, the relationship between diarrhoea morbidity and each flooding factor was analyzed using a Pearson correlation coefficient.

\section{Dataset for flooding analysis}

Topographical data for the study area were obtained from the Shuttle Radar Topography Mission, with a spatial resolution of $90 \mathrm{~m}$. Daily precipitation data were obtained from the Dhaka-Banani precipitation observatory provided by the Bangladesh Water Development Board.

\section{Flood analysis method using a numerical model}

The flood model used in this study was a two-dimensional unsteady flow model with rainfall calculated according to a shallow-water equation (JSCE, 1999)

$$
\begin{aligned}
& \frac{\partial h}{\partial t}+\frac{\partial M}{\partial x}+\frac{\partial N}{\partial y}=q_{\text {rain }} \\
& \frac{\partial M}{\partial t}+\frac{\partial u M}{\partial x}+\frac{\partial v M}{\partial y}=-g h \frac{\partial H}{\partial x}-g n^{2} u \frac{\sqrt{u^{2}+v^{2}}}{h^{\frac{1}{3}}} \\
& \frac{\partial N}{\partial t}+\frac{\partial u N}{\partial x}+\frac{\partial v N}{\partial y}=-g h \frac{\partial H}{\partial y}-g n^{2} v \frac{\sqrt{u^{2}+v^{2}}}{h^{\frac{1}{3}}}
\end{aligned}
$$

where $h$ is the water depth (m); $M, N$ are the $x, y$ direction flux $\left(\mathrm{m}^{2} / \mathrm{s}\right) ; u, v$ are velocity in the $x, y$ direction $(\mathrm{m} / \mathrm{s}) ; H$ is the water level $(\mathrm{m}) ; q_{\text {rain }}$ is the rainfall intensity per unit area $(\mathrm{m} / \mathrm{s})$; and $g$ is the acceleration of gravity $\left(\mathrm{m} / \mathrm{s}^{2}\right)$. We only considered flooding caused by rainfall because the city area is protected from flooding from the riverside by an embankment. To solve the equation, this method employed a leapfrog difference scheme using Cartesian coordinates.

\section{Ratio of land occupied by buildings}

Since buildings in Dhaka City are densely concentrated, we considered the ratio of land occupied by buildings. A roughness coefficient was calculated using the following equation:

$$
\begin{aligned}
& n^{2}=n_{0}^{2}+0.02 \times \frac{\theta}{1-\theta} \times h^{\frac{4}{3}} \\
& n_{0}^{2}=\frac{n_{1}^{2} A_{1}+n_{2}^{2} A_{2}+n_{3}^{2} A_{3}}{A_{1}+A_{2}+A_{3}}
\end{aligned}
$$

where $n\left(\mathrm{~s} / \mathrm{m}^{1 / 3}\right)$ is a synthetic roughness coefficient that considered the resistance of the building; $n_{0}\left(\mathrm{~s} / \mathrm{m}^{1 / 3}\right)$ is a synthetic roughness coefficient that considered land use; $n^{1-3}(\mathrm{~s} /$ $\left.\mathrm{m}^{1 / 3}\right)$ is Manning's coefficient; $h$ is the water depth $(\mathrm{m}) ; \theta$ is

the ratio occupied by buildings; and $A$ is the land area $\left(\mathrm{m}^{2}\right)$. Subscripts 1-3 denote farmland, road and other land use. The roughness coefficients obtained from the model (PWRI, 1998) were $0.060,0.047$ and 0.050 for farmland, road and other land use, respectively.

In this method, the building ratio should be uniformly set for each grid. This ratio was classified into four types based on the following characteristics, high density of buildings; 0.80 (blue); low density of buildings; 0.50 (light blue); airports (purple); and empty space (yellow and white), as shown in Figure 2.

The percentages of building areas were defined by satellite images as per Figure $2 b$. In the case where an accurate and well-managed geographical dataset is available, each grid can be assigned an individual building occupied ratio. However, in this study, to simplify the setting for determination of building occupied ratio, the target area was separated into three types of building area (none, middle density and high density) manually. After that, 5 samples $\left(0.5 \mathrm{~km}^{2}\right)$ were extracted from each separated building area respectively to obtain the actual ratio as an average percentage of each building area $(0 \%, 50 \%$ and $80 \%)$.

\section{Method used to consider drainage and sewerage}

The sewerage and drainage systems were considered in the flood model, taking particular note of the municipal effluent through the use of a simplified method. As mentioned in the paragraph on the study area, Dhaka City is highly dependent on pumping for its municipal effluent. Therefore, we assumed that the total drainage capacity of grids in the pumping-covered area was the same as the total capacity of the pumps. The pumps located from north to south along the Briganga River (Figure 1) have a capacity of $22.5 \mathrm{~m}^{3} / \mathrm{s}$, $20.0 \mathrm{~m}^{3} / \mathrm{s}$ and $22.5 \mathrm{~m}^{3} / \mathrm{s}$. The total capacity of the pumps was assigned to the area covered by the pumps, which was $150 \mathrm{~km}^{2}$, and this area was indicated by the building-occupied areas colored blue and light blue in Figure 2. Therefore, each grid had a drainage capacity of $37 \mathrm{~mm} /$ day, and we assumed

(a)

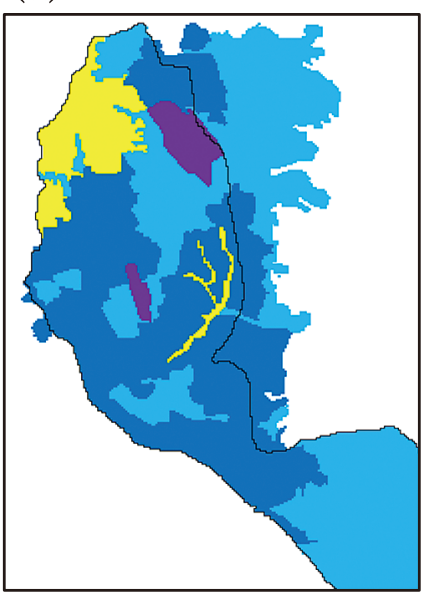

Figure 2. (a) Classification of the ratio occupied by buildings: Blue indicates 0.80 , light blue indicates 0.50 , yellow and white indicate unoccupied space and purple indicates an airport. (b) Satellite image taken by SPOT on 27 February, 2010 
that each grid was able to drain floodwater equally through the rainy season. The flooding simulation was started from the dry condition because April, which was set as the beginning of the simulation, is the end of the dry season.

\section{RESULTS AND DISCUSSION}

\section{Flood analysis}

Figure 3 shows the flood simulation results. The model results of the extent of the flood area were validated by satellite images taken by an Aqua Moderate Resolution Imaging Spectroradiometer (MODIS) on 1 May, 20 June and 3 August, 2007, when Dhaka City was flooded because of severe rainfall. In satellite images shown in Figure 3a, blue indicates flooding, and the areas in dense navy blue indicate a high depth of flooding. Green indicates an area of vegetation, and brown, clearly seen in the May 2007 satellite image, indicates areas with little vegetation. In particular, the dark brown areas on the lower left indicate concentrations of buildings.

\section{(a)}

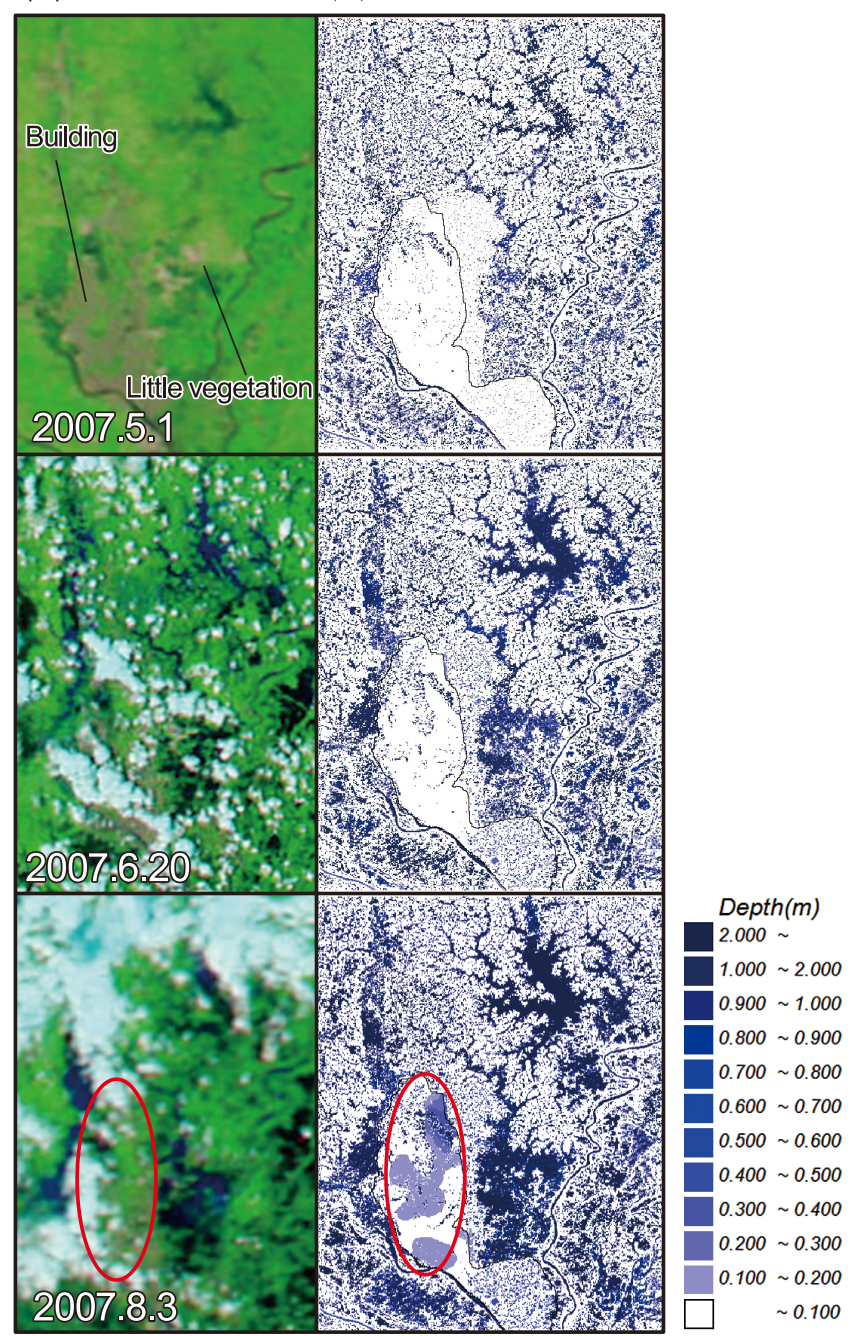

Figure 3. (a) Satellite image taken by Aqua MODIS on 1 May, 20 June, and 3 August, 2007. (b) Simulation results
Compared to the flooded area in the satellite image in Figure $3 \mathrm{~b}$, the simulation results successfully reproduced the extent of the flood area and its changes during several months of the rainy season. The changes from the less-flooded condition in May 2007, to the mid-flooding condition in June 2007, and then to the severely flooded condition in August 2007 were reproduced accurately. Although the part outlined in red denoting the comparison of August 2007 is only the simulated flood result, this can be classified as an area with a very dense concentration of buildings; the extent of the flood area cannot be clearly identified because of the resolution of the satellite image. From this comparison, it can be concluded that the flood model can reasonably simulate the occurrence of flooding. Several researchers pointed out the effectiveness on the dependency of sources for the infectious water risk (Thi et al., 2011; Amano et al., 2013); however, in the case of Dhaka City, a uniform degree of floodwater contamination is assumed because there are many ponds to discard domestic wastewater throughout the city.

The simulated flood depth over time is shown in Figure 4. The simulation results were qualitatively validated by information based on interview surveys of local people because no community properly investigated the flood depth. According to the information collected from residents, in the past 10 years, the floodwater depth for residents in Dhaka City has usually been from ankle to chest height. Thus, in each flooded area identified, flood depth was within the actual range. In addition, the difference in flood duration between persistently flooded areas (No. 7, 8, 9) and other areas that were classified as short duration (No. 1, 2, 3), long duration (No. 4, 5, 6) and non-flooded (No. 10) was reproduced well.

In terms of the validation of flooding duration, the simulated flooding duration was shorter than that reported by the residents overall. Residents said flooding for several days was observed in the short-term flooding area (No. 1, 2, 3), flooding for several months was observed in the long-term flooding area (No. 4, 5, 6), and persistent flooding was observed in the persistent-flooding area (No. 7, 8, 9). However, flooding was not simulated in the short-term areas (No. 1, 2, 3); two long-term areas (No. 5, 6) were not simulated; one month of flooding was simulated in area No. 4; and the simulated flooding lasted several months in the persistent flooding areas (No. 7, 8, 9). These errors seems to be reproduced because of sewage and drainage. If the flooding model considers garbage concentration, the duration of simulated flooding becomes longer than the present results. However, it does not influence the relative differences of flooding characteristics.

\section{Diarrhoea incidence}

Figure 5 shows the changes in flood depth and morbidity. First, we found that there were predisposing causes for contracting diarrhoea in the non-flooded areas because the morbidity was present in the pre- and post-monsoon season, even though flooding did not occur at that time. As Mollah et al. (2009) mentioned in their paper, this risk might be due to food, drinking water or hand-washing customs, which were not related to the flooding. Second, we found that flooding has an influence on diarrhoeal incidence because morbidity increased in the mid-monsoon season when flooding occurred, and this increase was observed in almost all com- 


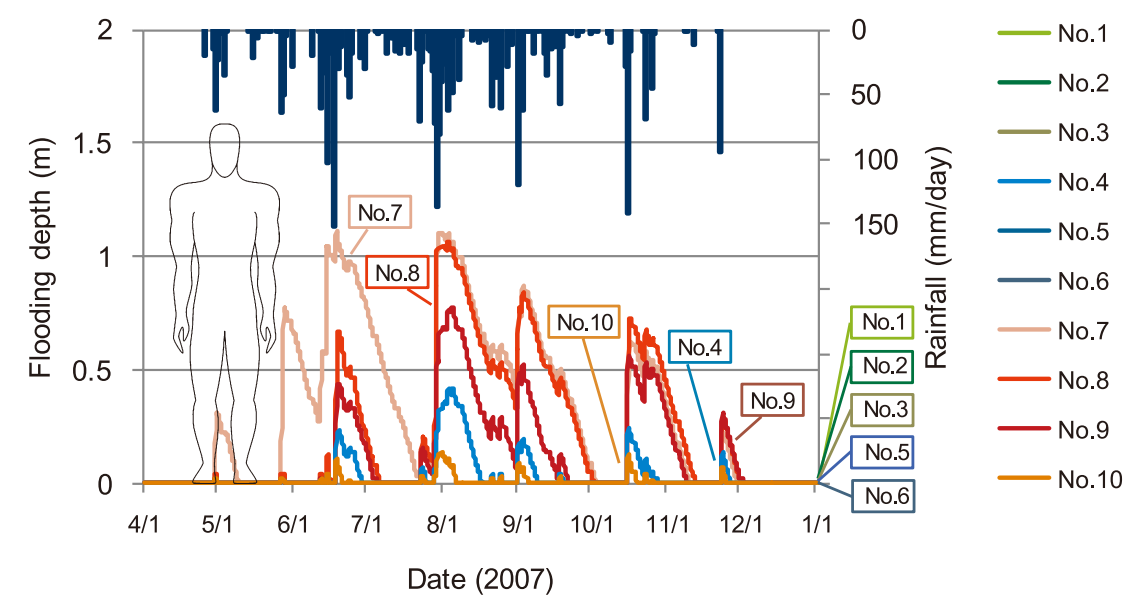

Figure 4. Flood depth over time with rainfall

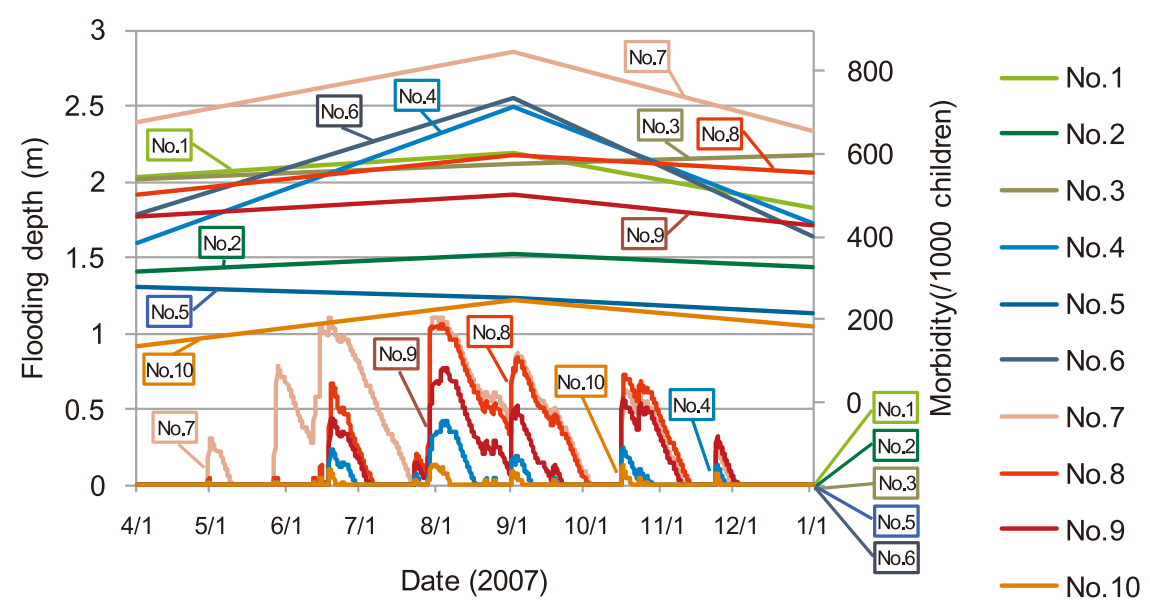

Figure 5. Comparison between flood depth over time and changes in morbidity

munities (9 out of 10). In community No. 7, which was in the most flood-prone area, morbidity was the highest in each season, and there tended to be a high rate of morbidity in long-duration flood areas (No. 4, 6) and persistent flooded area (No. 7). However, there is a possibility that the increased morbidity was not due to flooding only since an increase was also observed in community No. 10, which was chosen as a non-flooded area; this might also be influenced by rainfall, temperature and humidity in the mid-monsoon season.

Regarding the accuracy of flood depth over time using the flood simulation model, in the areas where morbidity significantly increased (No. 4, 6, 7), flood depth was high in communities No. 7 and 4; however, flooding was not identified in community No. 6. Flooding in community No. 6 might have been caused by riverside water, which is difficult to simulate.

Figure 6 compares the morbidity and maximum flood depth in each season. First, relatively lower morbidity was observed at the area with a maximum flooding depth of $0.1-$ $0.2 \mathrm{~m}$, and higher morbidity was observed at the area with a maximum flooding depth of $0.7-1.2 \mathrm{~m}$. However, a correlation that rejects the null hypothesis was not observed in pre(correlation coefficient $[\mathrm{CC}]=0.44$, $\mathrm{p}$-value $[P]=0.21$ ),



Figure 6. Relationship between morbidity and maximum flood depth in pre-, mid- and post-monsoon season

mid-monsoon season $(\mathrm{CC}=0.45, P=0.15)$ and postmonsoon seasons $(\mathrm{CC}=0.57, P=0.87)$.

This relationship seems to be due to a predisposition for contracting diarrhoea unrelated to flooding. One supposed cause of this relation is socioeconomic status. People in lower socioeconomic positions may live in areas with more 




Figure 7. Comparison between morbidity and flood parameters (maximum flood depth, maximum flood duration and accumulated flood depth)

severe waterlogged conditions (Mollah et al., 2009). As a result, a similar relationship was observed in pre- and post-monsoon seasons. Second, the correlation coefficient was not that different in each season. Although morbidity increased because of flooding, the gradient of diarrhoeal vulnerability seems to be due to socioeconomic status.

Figure 7 compares the correlation coefficient regarding the relationship between flood factors and morbidity. We assessed this relationship using not just maximum flood depth, but also maximum duration and accumulated flood depth. Although the correlation coefficient was high in the case of duration, which was 0.57 in the pre-monsoon season, 0.53 in the mid-monsoon season and 0.61 in the post-monsoon season, the difference was not large. Flood duration tended to be higher in areas where flood depth was also high. Therefore, we found that the correlation relationship was not different when comparing between duration and accumulated flood depth, as well as by comparison with flood depth.

This study quantitatively assessed the relationship between flood parameters and morbidity throughout the rainy season. The results supported the theory by Mollah et al. (2009) that diarrhoea risk is high in flood-prone areas. Based on the foregoing, the flood simulation model can be a useful tool for evaluating the influence of flooding on diarrhoea cases, although social conditions should be carefully considered (Hashimoto et al., 2013). The advantages of the flooding simulation are to be able to show the distribution of the diarrhoeal risk omitting the effort of collecting the observed data, and to estimate the diarrhoeal risk caused by flooding that has never occurred in the past. To achieve a more accurate estimate, an examination of resident's behavior during flooding conditions and social customs in flood prone areas will be required.

In terms of the applicability of this algorithm, places that have sufficiently many pollution sources are suitable for the assumption that floodwater is contaminated uniformly. In the case of places that have less pollution sources, a simple comparison between flooding conditions and diarrhoeal risk is difficult and the algorithm needs to consider advection because there is variation in the distribution of the pollution concentrations.

Our study had several limitations. First, the data for drainage and sewerage were somewhat faulty. To be precise, operational records of the main pumps, emergency pumps and the location of the pipes where garbage clogs occurred were not considered in the flooding model. Water logging in several low-income communities occurs because of problems with the drainage system (Mollah et al., 2009). Consequently, detailed drainage data should be collected for further research.

Second, the data for validating the flood simulation results were faulty. All the validation conducted in this study was qualitative. To quantitatively validate the model, a flood mark and flood depth record using a water-stage recorder would be helpful.

Third, since the target communities were small, clarifying the relationship between diarrhoeal incidence and flooding was difficult. If we had large datasets, we would have more statistically meaningful results.

Fourth, in this method, we did not consider hydraulic advection because many pollution sources such as ponds and backflow of sewage water originate from manholes. However, the situation is singular for Dhaka City due to high-population and high-building density. To apply this method to other areas, especially broad non-urban areas, we should consider hydraulic advection (Amano et al., 2013).

\section{CONCLUSIONS}

In this study, flooding in Dhaka City was simulated by a numerical flood simulation model, and its relationship to morbidity was investigated.

This flood model was found to reasonably simulate flooding after validating it using satellite observations of flooding and qualitative information regarding flood depth and duration from interviews of residents. Furthermore, we found that a consideration of drainage and sewerage greatly affects the accuracy of the simulation for flooding duration in the case of analysis over several months.

We found that there is a predisposing cause such as socioeconomic status for contracting diarrhoea without flooding from a comparison of maximum flood depth over time and changes in morbidity obtained from interview surveys. Furthermore, we also found that flooding has an influence on contracting diarrhoea, where morbidity increased in 9 out of 10 areas, and the areas where this increase was large were those prone to long durations of flooding and persistently flooded areas.

We quantitatively examined the relationship between morbidity and flooding using maximum flood depth, maximum flood duration and accumulated flood depth. As a result, we found that there was no significant difference with respect to a comparison of each flood factor. Furthermore, the relationship between flooding and morbidity was considered to be due to predisposing causes, as this relationship was present in the absence of flooding.

For further research, to precisely clarify the relationship between flooding and diarrhoeal incidence, the consideration of social factors affecting diarrhoeal incidence could be suggested, and a mechanism for identifying the route of infectious disease should be precisely clarified. Furthermore, to obtain reliable numerical flooding simulation results, observing the water depth in low-income-community areas would be indispensable for validation. 


\section{ACKNOWLEDGMENTS}

This study was conducted as part of the University of Yamanashi Global Centre of Excellence Program for Evolution of Research and Education on Integrated River Basin Management in the Asian Region, directed by the Ministry of Education, Culture, Sports, Science and Technology of Japan. Also, this research was partly supported by JICA/JST, SATREPS (Science and Technology Research Partnership for Sustainable Development).

\section{REFERENCES}

ADB. 2007. Proposed loans and technical assistance grant. People's Republic of Bangladesh: Dhaka water supply sector development program.

Ahern M, Kovats RS, Wilkinson P, Few R, Matthies F. 2005. Global health impacts of floods: epidemiologic evidence. Epidemiological Reviews 27: 36-46. DOI: 10.1093/epirev/ mxi004.

Amano A, Sakuma T, Kazama S, Gunawardhana L. 2013. Evaluation of diarrhea disease risk attributed to inundation water use on a local scale in Cambodia using hydrological model simulations. River Systems 20: 185-196. DOI: 10.1127/1868-5749/2012/0064.

Azharul Haq K. 2006. Water Management in Dhaka. International Journal of Water Resources Development 22: 291-311. DOI: 10.1080/07900620600677810.

Baqir M, Sobani ZA, Bhamani A, Bham NS, Abid S, Farook J, Beg MA. 2012. Infectious diseases in the aftermath of monsoon flooding in Pakistan. Asian Pacific Journal of Tropical Biomedicine 2: 76-79. DOI: 10.1016/s2221-1691(11)601949.

Dewan AM, Yamaguchi Y. 2009. Using remote sensing and GIS to detect and monitor land use and land cover change in Dhaka Metropolitan of Bangladesh during 1960-2005. Environment Monitoring Assessment 150: 237-249. DOI: 10.1007/s10661008-0226-5.

Harris AM, Chowdhury F, Begum YA, Khan AI, Faruque ASG, Svennerholm A-M, Harris JB, Ryan ET, Cravioto A, Calderwood SB, Qadri F. 2008. Shifting prevalence of major diarrheal pathogens in patients seeking hospital care during floods in 1998, 2004, and 2007 in Dhaka, Bangladesh. The American Journal of Tropical Medicine and Hygiene 79: 708-714.

Hashimoto M, Suetsugi T, Sunada K, Ichikawa Y, Kondo N, Nishida K. 2012. Study on sensitivity analysis of main factors for inundation in Dhaka City, Bangladesh. Advances in River Engineering 18: 487-492.

Hashimoto M, Suetsugi T, Sunada K, Ichikawa Y, Kondo N, Nishida K. 2013. Estimation of diarrhoea incidence through flooding simulation in low-income community areas in Dhaka City, Bangladesh. Southeast Asian Water Environment 5: $67-73$.

Hashizume M, Armstrong B, Wagatsuma Y, Faruque AS, Hayashi T, Sack DA. 2008. Rotavirus infections and climate variability in Dhaka, Bangladesh: a time-series analysis. Epidemiology and
Infection 136: 1281-1289. DOI: 10.1017/S0950268807009776.

Hashizume M, Wagatsuma Y, Hayashi T, Saha SK, Streatfield K, Yunus M. 2009. The effect of temperature on mortality in rural Bangladesh - a population-based time-series study. International Journal of Epidemiology 38: 1689-1697. DOI: 10.1093/ije/dyn376.

ICDDR B. 2007. Responding to the 2007 floods: Record numbers of patients seek care at ICDDR,B's Dhaka Hospital. Health and Science Bulletin 5: 1-5.

JICA. 1991. Master Plan Study for Greater Dhaka Protection Project, FAP 8A.

JSCE. 1999. The Collection of Hydraulic Formulae, Maruzen shuppan: Tokyo.

Kazama S, Aizawa T, Watanabe T, Ranjan P, Gunawardhana L, Amano A. 2012. A quantitative risk assessment of waterborne infectious disease in the inundation area of a tropical monsoon region. Sustainability Science 7: 45-54. DOI: 10.1007/ s11625-011-0141-5.

Kunii O, Nakamura S, Abdur R, Wakai S. 2002. The impact of health and risk factors of the diarrhoea epidemics in the 1998 Bangladesh floods. Public health 116: 68-74. DOI: 10.1038/ $\mathrm{sj} / \mathrm{ph} / 1900828$.

Mark O, Weesakul S, Apirumanekul C, Aroonnet SB, Djordjević S. 2004. Potential and limitations of 1D modelling of urban flooding. Journal of Hydrology 299: 284-299. DOI: 10.1016/j.jhydrol.2004.08.014.

MoEF, UNEP, BCAS. 2006. Dhaka City State of Environment 2005, UNEP; 96.

Mollah KA, Nishida K, Kondo N, Yamagata Z. 2009. Children's Health Deficits due to Diarrhoea: Effects of Water Supply and Sanitation Systems in Slums with Different Water Logging Conditions. Journal of Water and Environment Technology 7: 277-291. DOI: 10.2965/jwet.2009.277.

PWRI. 1998. Flooding simulation manual - A guide of the simulation and inspection of the new model -, Technical Memorandum of Public Works Research Institute; 137.

Rashid SF. 2000. The urban poor in Dhaka City: their struggles and coping strategies during the floods of 1998. Disasters 24: 240-253. DOI: 10.1111/1467-7717.00145.

Reacher M, McKenzie K, Lane C, Nichols T, Kedge I, Iversen A, Hepple P, Walter T, Laxton C, Simpson J. 2004. Health impacts of flooding in Lewes: a comparison of reported gastrointestinal and other illness and mental health in flooded and non-flooded households. Communicable Disease and Public Health 7: 39-46.

Schwartz BS, Harris JB, Khan AI, Larocque RC, Sack DA, Malek MA, Faruque ASG, Qadri F, Calderwood SB, Luby SP, Ryan ET. 2006. Diarrheal epidemics in Dhaka, Bangladesh, during three consecutive floods: 1988, 1998, and 2004. The American Journal of Tropical Medicine and Hygiene 74: 1067-1073.

Thi MH, Watanabe T, Fukushi K, Ono A, Nakajima F, Yamamoto K. 2011. Quantitative risk assessment of infectious disease caused by water borne Escherichia coli during floods in cities of developing countries. Journal of Japan Society on Water Environment 34: 153-159.

UNICEF, WHO. 2009. Diarrhoea: Why children are still dying and what can be done, UNICEF and WHO; 58.

WorldBank. 2010. Country Assistance Strategy for the People's Republic of Bangladesh for the Period FY-11-14; 44. 